\title{
Justification of ways to increase the durability of tillage working bodies
}

\author{
Leonid Babitskiy ${ }^{1}$, Vadim Moskalevich ${ }^{1, *}$, and Sergey Mischuk ${ }^{1}$ \\ ${ }^{1}$ FSAEI HE "V.I. Vernadsky Crimean Federal University", Academy of Life and Environmental \\ Sciences, 295492, Russia
}

\begin{abstract}
Based on an analysis of the features of operation of tillage working bodies proposed methods to increase their durability, combining intermittent overlaying welding surfaces by wear-resistant materials and influence deep cold. Justified stand options for cryogenic influence on details of tillage machinery. The results of the experiment for the realization of the offered methods of durability for example loosening claws of the tiller are given
\end{abstract}

\section{Problem in general form and its connection with important scientific and practical tasks}

The increase in working speed of tillage and improved soil compaction due to their multiple passes of the machines on the ground led to an increase in various types of loads to working bodies, including percussion. Therefore, designing machines on methodologies developed in the middle of the last century, without taking into account contemporary trends, does not provide them with adequate reliability. Work is being done on "Justification settings and increase the reliability of tillage working bodies by bionics likeness for ecological agriculture of the Crimea", which is part of the research plan of FSAEI HE "V.I. Vernadsky Crimean Federal University".

\section{Analysis of recent achievements and publications}

The technology of manufacturing parts of working bodies of tillers, representing non-planar parts of complex shape with convex-concave curvature of the working surface предложена at the Department of mechanical and technical service of Academy of Life and Environmental Sciences. To improve the work of such resource details the hardening should be carried out in accordance with self-sharpening their blades [1]. At surfacing of hard alloy sections for bionics reasonable parameters on working surfaces of ploughs and cultivators claws due to the effects of the soil wrapping formed protrusions decreases the amount of solid particles of soil, contact with them, and their pressure, resulting in reduced wear rate $[2,3]$.

\footnotetext{
${ }^{*}$ Corresponding author: v_moskalevich@mail.ru
} 


\section{The formulation of the goals and objectives of the work}

Agricultural machinery factories used outdated technology manufacturing parts of tillage machines, as a result of the past have many technological defects, which significantly reduce the reliability of construction machinery. This refers to details such as ploughs, cultivators, discs of harrows, as well as flexible racks and springs. In this connection, it is relevant to search for new solutions to the problem of improving the durability of the working bodies of the tillage machines without increasing their cost.

\section{Presentation of the basic material investigations}

Considering tillage machine as a constructive system, it can highlight the most critical elements, which influence on reliability on construction. These elements include the cutting parts, flexible racks and springs, as well as percussive mechanisms. Recent also includes spring and movable parts with impacts ends.

Consider operational factors causing wear and tear on items under consideration.

Soil particles have an abrasive and multiple impacts on the surface of cutting parts [4].

The impact ends of the movable parts of percussive mechanisms perceive shock loads. Flexible racks and springs are subjected to cyclic loads. Drums and cyclical loads cause surface wear and volumetric fatigue details. In addition, reactive solutions of salts, which are contained in the soil, corrosive surfaces, which works in conjunction with abrasive wear and fatigue.

In the manufacture of the above elements used steels with a carbon content of 0.4 to $0.9 \%$. Additionally they may content manganese, chromium and silicon. The peculiarity of these steels is the presence of residual austenite, since its transformation into martensite ends at temperatures below $0^{\circ} \mathrm{C}$. The higher the carbon content and more of alloying elements in steel, the lower the temperature the completion of martensite transformation.

For increase of durability of tillage working bodies are encouraged to expose their vital parts of cryogenic temperature action. Deep cold can act as the tail of manufacturing technology, as well as to apply after restoring the parts guy and welding during repair. Cryogenic temperature action will allow the correct technological defects, reducing the heterogeneity of the hardness and strength of the material components. Improvement of the physical and mechanical characteristics of the material parts machine resulting from tillage cryogenic temperature action will reduce the intensity of abrasion, fatigue and chemical wear, increase durability cutting parts, as well as flexible racks, percussive elements and springs.

To study of modes of technology the deep cold processing of parts of tillage machines offered laboratory stand, which provides slow cooling parts, their exposure given the low temperatures, the subsequent mooth temperature rise to normal conditions, as well as the final heating and cooling parts to relieve internal stresses in the material.

Scheme of laboratory stand for cryogenic temperature action parts of tillage machines is presented in Fig. 1. 


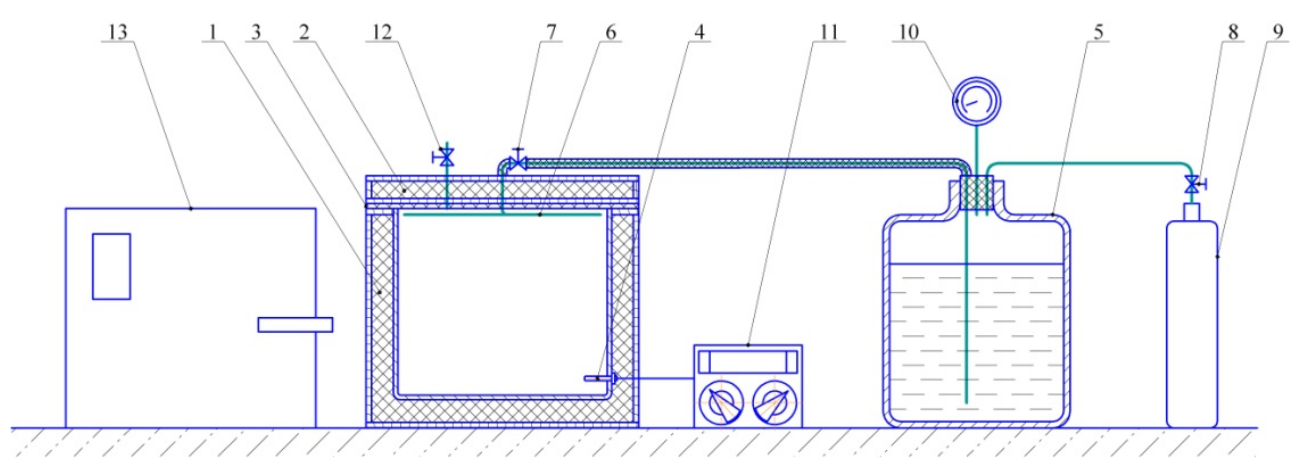

Fig. 1. Scheme of laboratory stand for cryogenic temperature action parts.

Main unit of laboratory stand is krioprocessor. Krioprocessor consists of the refrigerator container 1. Download details in refrigerator container 1 is carried out through the top cap 2 with gasket 3. Inside the refrigerator container 1 temperature sensor 4 is installed. Krioprocessor has a device for adjustable feeder in refrigerator container 1 liquid nitrogen from the vessel 5 and release it from the container. It has coil 6, which is made of copper tubes bent into a spiral shape, and adjusting a faucet 7 . Vessel 5 is connected through the pressure relief valve 8 with cylinder 9 with compressed dry air. To control the vapour pressure of nitrogen vessel 5 has pressure gauge 10. Krioprocessor is equipped with system 11 control cryogenic temperature action regimes. The cap 2 has an adjustable valve 12 to release the nitrogen vapor. To relieve internal stresses in the material of parts by their smooth heating and cooling used cupboard 13.

The parts to be processed by deep cold are loaded into the refrigerating container 1 of the cryoprocessor. The operator of the stand smoothly opens valve 7. Under the pressure of nitrogen vapor in vessel 5, liquid nitrogen enters the coil 6 with a small flow rate, gradually cooling the metal container 5 with the details contained in it from the normal temperature $\left(+20^{\circ} \mathrm{C}\right)$ to the boiling point of liquid nitrogen $\left(-196{ }^{\circ} \mathrm{C}\right)$. Nitrogen vapor escapes from container 1 to atmosphere through valve 12. After cooling, installation operator the stand completely opens valve 7 and, via reduction valve 8 , releases compressed dry air from cylinder 9 to vessel 5 , thus increasing the flow of liquid nitrogen to the refrigerating container 1 of the cryoprocessor. As a result, liquid nitrogen fills the parts in the container 1. In this state, the parts are kept at the boiling point of liquid nitrogen $\left(-196{ }^{\circ} \mathrm{C}\right)$ for a period of time depending on their size and material. At the end of the shutter speed, operator of the stand blocks the supply of compressed dry air from the cylinder 9 to the vessel 5, closes the valve 7, stopping the supply of liquid nitrogen to the refrigerating container 1 of the cryoprocessor and fully opens the exhaust valve 12 . Liquid nitrogen gradually evaporates from the container 1 to the atmosphere. In this case, the temperature in the container 1 of the cryoprocessor smoothly rises from $\left(-196{ }^{\circ} \mathrm{C}\right)$ to normal $\left(+20^{\circ} \mathrm{C}\right)$.

After completion of cryoprocessing, the operator moves the parts from the cryoprocessor to the cupboard 13. In the cupboard 13 is performed stress relief in the details. To do this, they are gradually heated from a normal temperature $\left(+20{ }^{\circ} \mathrm{C}\right)$ to a temperature $\left(+150{ }^{\circ} \mathrm{C}\right)$, held at this temperature and slowly return to a normal temperature $\left(+20{ }^{\circ} \mathrm{C}\right)$.

When justifying the parameters of the cryoprocessor capacity for parts, it is necessary to take into account their largest geometrical dimensions and the required useful volume. From the point of view of manufacturability, it is advisable to take a cylindrical shape of the container for machined parts with an open top. The internal diameter of a cylindrical container is determined by the equation: 


$$
d=A+\Delta_{A},
$$

where $A$ - is the maximum size of the parts;

$\Delta_{\mathrm{A}}$ - parameter of the size reserve, which makes it possible to exclude damage to the container walls by the parts being processed.

The usable volume of capacity for parts is determined by the equation:

$$
V=V_{D}+\Delta_{V},
$$

where $V_{D}$ - is the volume occupied by the parts that can be determined experimentally;

$\Delta_{\mathrm{V}}$ - volume margin parameter that allows liquid nitrogen to cool the parts being processed efficiently. To substantiate the optimal value of this parameter, it is necessary to conduct experimental studies.

The outer diameter of the cylindrical container is determined by the equation:

$$
D=d+2 t_{C},
$$

where $\mathrm{d}-$ is the internal diameter of the cylindrical container;

$t_{C}-$ wall thickness of the cylindrical container.

The height of the cylindrical container is found from the equation for the volume of the cylinder:

$$
h=\frac{4 V}{\pi d^{2}},
$$

where $V$ - effective volume of the container for the parts being machined;

$\mathrm{d}$ - internal diameter of a cylindrical container.

Considering the shape of the container for parts parts (cylinder with an open base), it is advisable to perform a cooling coil of the cryoprocessor in the form of a spiral with a uniformly increasing coil pitch. This condition corresponds to the spiral of Archimedes, whose equation in polar coordinates is:

$$
r_{i}=r_{0} \varphi,
$$

where $r_{\mathrm{i}}$ - current value of the radius-vector of the spiral in polar coordinates;

$r_{0}$ - initial value of the radius vector of the spiral in polar coordinates;

$\varphi$ - angle of rotation of the initial radius vector of the spiral in polar coordinates.

The mass of liquid nitrogen for cooling the refrigerating container of the cryoprocessor is determined from the equations of heat balance. The final expression is:

$$
m_{N}=\frac{c m \Delta t}{r},
$$

where $m_{N}$ - mass of liquid nitrogen;

$c$ - specific heat capacity of the material of the parts cooling in the refrigerating container of the cryoprocessor;

$m$ - mass of parts processed by cold;

$\Delta t$ - temperature difference between the initial temperature of the parts and the boiling point of liquid nitrogen;

$r$-specific heat of vaporization of nitrogen. 
During the experiments, a layer of wear-resistant material (hard alloy) was deposited intermittently on the working surfaces of the tips of the loosening claws of the cultivator. After air cooling, the intermittently deposited parts of the working bodies were exposed to deep cold (cryo-processing) in the temperature range $\left(-78 \ldots-196{ }^{\circ} \mathrm{C}\right)$ for 72 hours, and then tempering at $\left(+150^{\circ} \mathrm{C}\right)$ for 3 hours.

The result of the influence of cryogenic cold on the physicomechanical properties of materials of parts of tillage was evaluated by the change in hardness and strength. It was established that after deep cold, the hardness of the base material (65G steel) increased from an average of 35.8 to $38.0 \mathrm{HRC}$ units, and the deposited layer - from 51.6 to 53.0 HRC. At the same time, the strength of the main material increased from 1063.8 to 1121.4 $\mathrm{MPa}$.

\section{Conclusions and prospects for further development in this area}

The obtained results are explained by the fact that when intermittent surfacing is performed by wear-resistant material on the working surfaces of parts, there is a significant nonuniform local heating of the part in the areas affected by the electric arc, as a result of which considerable internal mechanical stresses arise in the material. Deep cold provides a more complete transformation of residual austenite to martensite in the material of parts and in the weld layer, as a result of which the hardness of their material significantly increases while simultaneously increasing the strength of the base material. The proposed method of hardening by exposure to deep cold (cryoprocessing) on parts of tillers with a hard wear resistant alloy intermittently deposited on their surface will increase the durability of tillage working bodies by increasing their wear resistance during tillage. The effect of use for working bodies subjected to cryogenic cold treatment is due to an increase in the resource of the cutting elements of the working bodies, an improvement in the mechanical characteristics of the flexible elements (leveling of the stiffness characteristic and an increase in resistance to cyclic fatigue), and a reduction in labor costs for the repair of the working bodies. Due to the increased service life of hardened blades and stabilization of spring stiffness, providing stable vibration and, as a result, reduction of traction resistance and dynamic loads on the working surfaces of the claws. For a cultivator, one set of claws is enough for a year, whereas when working with serial claws without cryoprocessing, it is necessary to purchase additional sets of claws due to their rapid wear. In addition, increasing the overall reliability of the working bodies helps to reduce the time of unproductive downtime of the unit. In further studies to improve the durability of soil tillage bodies, the parameters of surfacing and cryoprocessing modes for various types of soil tillage machines will be optimized.

\section{References}

1. L.F. Babitsky, V.Yu. Moskalevich, News of the Ukrainian Academy of Agricultural Sciences, v. 5, pp. 35-42 (2017)

2. L.F. Babitsky, V.Yu. Moskalevich, Materials of the XX international scientific and practical conference, pp. 262-266 (2015)

3. V.Yu Moskalevich, Motrol. An international journal of agri-food industry machinery, Vol. 14, No 6, pp. 157-162 (2012)

4. M.M. Tenenbaum, T.F. Akhmetshin, Study of the working bodies of machines for the cultivation and harvesting of fruit crops and grapes, pp. 91-97 (1987) 